\title{
A Multiplayer Learning Game based on Mixed Reality to Enhance Awareness on Archaeology
}

\author{
Mathieu Loiseau ${ }^{1, *}$, Élise Lavoué ${ }^{2}$, Jean-Charles Marty ${ }^{3,4}$, Sébastien George ${ }^{5}$ \\ ${ }^{1}$ LIDILEM, Université Stendhal Grenoble 3 \\ ${ }^{2}$ Magellan, IAE Lyon, Université Jean Moulin Lyon 3 \\ ${ }^{3}$ Université de Lyon, CNRS \\ ${ }^{4}$ Université de Savoie, LIRIS, UMR5205, F-69621, France \\ ${ }^{5}$ LUNAM Université, Université du Maine, EA 4023, LIUM, 72085 Le Mans, France
}

\section{Abstract}

Our research deals with the development of a new type of game-based learning environment: (M)MORPG based on mixed reality, applied in the archaeological domain. In this paper, we propose a learning scenario that enhances players' motivation thanks to individual, collaborative and social activities and that offers a continuous experience between the virtual environment and real places (archaeological sites, museum). After describing the challenge to a rich multidisciplinary approach involving both computer scientists and archaeologists, we present two types of game: multiplayer online role-playing games and mixed reality games. We build on the specificities of these games to make the design choices described in the paper. We also present three modular features we have developed to support independently three activities of the scenario. The proposed approach aims at raising awareness among people on the scientific approach in Archaeology, by providing them information in the virtual environment and encouraging them to go on real sites. We finally discuss the issues raised by this work, such as the tensions between the perceived individual, team and community utilities, as well as the choice of the entering point in the learning scenario (real or virtual) for the players' involvement in the game.

Keywords: Game-Based Learning, Multiplayer Game, Mixed Reality, Learning Scenario, Archaeology

Received on 22 January 2014, accepted on 02 June 2014, published on 26 August 2014

Copyright ( 2014 Mathieu Loiseau et al., licensed to ICST. This is an open access article distributed under the terms of the Creative Commons Attribution licence (http://creativecommons.org/licenses/by/3.0/), which permits unlimited use, distribution and reproduction in any medium so long as the original work is properly cited.

doi: $10.4108 /$ sg.1.3.e3

\section{Introduction}

We believe that Game-Based Learning (GBL) can significantly enhance learning, and does so in diverse application domains. In the last years, we have set up number of experiments using GBL environments. Immersing learners in such digital environments is a good way to support their learning, and especially their level of motivation. However, a well-known limitation of GBL learning is the difficulty for learners to apply in real life the concepts they learn in the game. Indeed, the objects manipulated in the game are a modelization of real life objects. To apply in real life the concepts acquired in game, learners need to become aware, to a certain extent, of the abstraction underlying the modelization. An operation, which we believe can be eased by manipulating directly the real life objects. We address this issue in this paper in a specific GBL environment: (M)MORPGs, which rely on the collaboration and interactions amongst

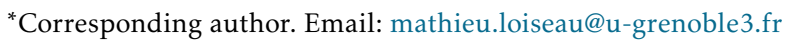

learners to increase their level of motivation. We present a multidisciplinary project called JANUS, launched by computer scientists and archaeologists in order to design and experiment an educational MORPG. Additionnally, the pluridisciplinary approach underlying the project is in itself a challenge, as we will explain in section 2 .

Archaeology is a particularly appropriate domain to apply both this mixed (virtual/real) GBL approach and collaborative learning: it directly depends on physical artefacts as the seminal input to the various and complementary subsequent processes inherent to the several subdomains of Archaeology. The first result of our joint ideas is a learning scenario described in section 4 that explains how to integrate activities in a virtual world (the game and web sites) and activities on archaeological sites or in museums. The design of this scenario is based on two types of games that we study in section 3: multiplayer online role-playing games and mixed reality games. Part of this scenario has been implemented in the form of three modular features that we describe in section 5 . 
In order to keep a strong motivation in the game, we have decided to organize a learning quest where students are grouped into guilds. During this quest, we mean to enhance the interrelationship of people inside their guilds, and the personal contributions of each student for the rest of the group (the community of learners). We also describe how we swap from activities in the virtual world to activities in the real world through a unique scenario. The idea here is to keep the same motivation and a continuous experience in the virtual game and at the museum or on the archaeological site. We finally conclude by drawing lessons about this work and by explaining generally the main research questions that have been raised and that we intend to address in the near future.

\section{Designing new GBL activities}

As explained earlier, we would like to propose a GBL approach for raising awareness among students on the scientific approach in Archaeology. This is why, computer scientists and archaeologists have launched a multidisciplinary project called JANUS, in order to design and experiment an educational MMORPG.

Basically, this educational environment must allow individuals or groups of users to embark on a quest for knowledge through the discovery of archaeological items. However, a major long term goal of the project is also to create a community around archaeology. Peripheral aspects such as promoting the cultural heritage and make people discover it through city walks are also to be considered.

These challenging objectives lead immediately to very complex questions: first of all, we believe that "learning by doing" is an interesting aspect to introduce in our learning sessions. This led us to consider how to take advantage of mixed (virtual/real) GBL features. In fact, even if general knowledge can be acquired in a virtual environment, more practical items must be studied on the archaeological site, in the museums or at the library. We can expect here that the motivation provided by a virtual game-based environment can be improved with challenges in the real world. A side effect of having part of the activities on cultural sites is actually to promote the cultural heritage. Second, the learning process is not necessarily an individual process. Current trends on teaching tend to introduce collaborative learning, involving groups of learners to gather, share and use knowledge to solve new problems. Collaborative learning features are thus also central in our research work. Third, some activities must be designed in order to generate collective debates, to produce new information, vital to the achievements of new social behaviours.

The project involves researchers in very different domains ranging from computer science to archaeology.
There is another challenge to this rich multidisciplinary approach: the emergence of a shared vocabulary and the understanding of the research questions emphasized in each area. Our first step was thus to list the different project requirements. We subsequently held several meetings that were dedicated to exchanging knowledge and approaches to problems. As the domains were quite large to cover, we decided to design a learning scenario that explains how to integrate activities in a virtual world (the game and web sites) and activities on archaeological sites or in museums.

To sum up, we were faced with the problem of designing a scenario where collaborative aspects are considered, where mixed (real/virtual) aspects are included, while respecting strong domain constraints (precise tasks to be taught). Furthermore, we wanted to integrate particular activities facilitating the emergence of an archaeological community. In order to understand well the domain constraints and because the requirements were somewhat vague, we decided to adopt an Agile software development process, following a Scrum approach [1]. We have therefore divided our projects into sprints ( 3 weeks periods) to build our scenario. As recommended in the Scrum methodology, we have gathered all the ideas of functionalities to be included in the scenario in a file called the "product backlog". At the beginning of each sprint, both the archaeologists and the computer scientists meet and discuss the new version of the scenario. Relevant changes can be performed as well as new ideas added in the product backlog. The team then decides what features have the highest priority in order to include them in the scenario for the next sprint.

Since collaborative and community aspects are concerned, we must clearly rely on multiplayer games and also consider the work carried out in mixed reality games in order to contextualize our real/virtual approach. We now present a state of the art for these domains and introduce more concrete examples on the scenario that is currently implemented in the project.

\section{State of the art}

\subsection{Multiplayer games}

Game-Based Learning (GBL) has the potential of improving training activities and initiatives thanks to its engagement, motivation, role-playing, and repeatability (failed strategies can be modified and tried again). Learning Games (LG) have proven to be useful to provide learners with pedagogical content in a ludic or/and realistic way [2]. However most LGs are played individually and learners evolve in the game without interaction with "real" learners. One way to enhance learning and engagement in the game is to allow collaboration by proposing a multiplayer environment. 
Currently, we observe the emergence and success of online multiplayer games in the world [3] and even in education [4]. Multiplayer Learning Games (MLG) usually immerse the players in a virtual 2D or 3D environment [5] and propose collaborative activities. This type of games can support development of a number of skills: strategic thinking, planning, communication, collaboration, group decision-making and negotiating skills [6]. Players learn not only from the game, but also from each others $[4,7]$. Unfortunately, these games usually allow collaboration only among a limited number of students inside the virtual world. Furthermore, collaboration occurs according to a predefined learning scenario, often regulated by a teacher. Learners have thus restricted possibilities of interaction with other learners. We believe that it is one of the main reasons why students tend to consider Computer-Based Learning Environments as unexciting.

Massively Multiplayer Online Games (MMOG) are games that are played online by hundreds of players simultaneously. They are nowadays predominantly played by digital natives. Educational MMOGs often work as tournaments and are based on competition between groups of students like in [8]. The most popular type of MMOG, and the sub-genre that pioneered the category, is the Massively Multiplayer Online Role-Playing Game (MMORPG). An MMORPG is "an immersive 3D world where hundreds or thousands of players connect simultaneously from all over the world in order to meet each other in a simulated reality" [9]. Many MMORPGs offer support for in-game guilds or clans that are groups of players coming together to share knowledge, resources and manpower to reach common goals. For example, World of Warcraft is an MMORPG set in a fantasy world (like "The Lord of the Rings"). The aim of the game is to conduct a series of missions, so-called quests, with progressive levels of difficulty. There is much international scientific research in the sociological and psychological fields that clearly demonstrates how this kind of game changes significant characteristics of the players; for example, the ability to be a group, to take on leadership, to manage roles and to interact in order to achieve a common goal $[10,11]$. We agree with Egenfeldt-Nielsen that "in a socio-cultural perspective, video games are the tools for constructing a viable learning experience, but not the learning experience per se. Video games mediate discussion, reflection, facts, and analysis facilitated by the surrounding classroom culture and the student's identity. In other words, video games are interesting not for their content but for the way new explorations initiate negotiations, constructions, and journeys into knowledge" [12].

So we can see interaction in an MMORPG as a condition for social learning [13]. Players exchange ideas, solve problems and create relationships, through communication technologies like chat or forum. Paraskeva, Mysirlaki and Papagianni have considered the functioning of online multiplayer educational games to highlight the importance of developing a strong sense of community among players to favor their motivation and engagement and the learning through a social experience [14]. The sense of belonging in a community (game community or learning community) intrinsically motivates students to participate in the game and increases their performance. Lavoué defines Social Learning Games (SLG) as "games that enhance learning by offering educational contents according to a learning scenario and by supporting a community that offers condition for social learning" [15]. The author highlights the different ways to enhance learning in SLG: the engagement in the game through the community, the mutual help in the community to make decisions in the game, the educational contents to initiate discussions in the community, the freedom in the community and the control in the game. MMORPGs therefore foster learners' engagement in the game [16] and create dynamic learning opportunities due to the community. Role-playing incites players to help each other to solve problems, by using their own different knowledge and capabilities. Voulgari and Komis also argue that MMOGs have the potential to meaningfully integrate a diversity of motivators, as well as opportunities for cognitive and social processes, and to support the learning of the content and the practice of social and interpersonal skills [17].

An important question addressed in this paper is how educational games can encourage effective collaborative learning and social knowledge building. For instance, a positive interdependence can be supported by using a jigsaw pedagogy [18]. According to Johnson, Johnson and Holubec, "positive interdependence is successfully structured when group members perceive that they are linked with each other in a way that one cannot succeed unless everyone succeeds" [19]. Within jigsaw pedagogy, each learner in a group becomes an expert on one aspect, and teaches it to the other group members, which is in itself inline with recommandation (iv) of [20]. An example of mobile learning games based on jigsaw pedagogy is Fort Ancient Adventure [21]. This game uses mobile technology to deliver location specific information for educational purposes. Furthermore, learner groups perform a complex task that is dependant on each group member's area of expertise. In this way, "success depends on the student's ability to listen, understand, communicate, and discuss an idea with others" [21].

Supporting collaborative activities among online players is one of the major challenges in the area of Massively Multiplayer Online Games (MMOG). For instance, Adam et al. propose a system in 
order to provide online community and collaboration services to MMOG players [22]. The implemented features distinguish CNG (Community Network Game) collaboration tools from a typical social networking website. They utilize an enhanced Peer-to-Peer (P2P) technology for the distribution of user-generated live video streams. Konert et al. propose a categorization and a theoretical model to combine game-based and community-based achievements [23]. They define new achievement types to bring community and collaboration in the game closer together, for instance user-generated achievements and user-based awarding of achievements based on votes.

Another major issue in our work is to combine three levels of communication and learning: individual, team (guild) and community. The players will be able to collaborate within their team and consequently to benefit from collaborative learning. They will also exchange information with other players and thus facilitate the emergence of a community interested in archaeology so that they will benefit from social learning. To design such a game, we will base our work on the four lessons given in [20] for the design of collaborative games:

(i) a collaborative game should introduce a tension between perceived individual utility and team utility;

(ii) individual players should be allowed to make decisions and take actions without the consent of the team;

(iii) players must be able to trace payoffs back to their decisions;

(iv) a collaborative game should bestow different abilities or responsibilities upon the players.

Meanwhile, we have to facilitate the emergence of a community of players interested in archaeology. In such a context, we will induce collaboration amongst the members of a same team, and competition between the players from different teams.

To our knowledge only one game focuses on the combination of these three levels in one system and is described in [24]. The authors "introduce methods and concepts of Woodment as a browser-based Serious Multiplayer Game to teach and explore a customizable learning content in a game-based and playful manner". The immersive environment sets the scene for a business simulation game in the field of logging: players can explore the island's 3D world, manage the company, react to unexpected events, fight for the victory of the team, communicate with others via in-game chat, level up and create learning content using the web interface. This game supports several levels of exchange (teams and global), but only by the way of a global chat and a team chat. In the course of the game, the players can take tests and answer quizzes individually or collectively. But there does not seem to be any connection between the educational content and the game itself, as the educational content can concern any topic. This can be considered a strength as it makes the game infinitely extendable - one question at a time - and repeatable, but it can also be perceived as a weakness as the conjunction of the business game and the quizzes can seem artificial to the learners. Here, we are developing a game under the form of a quest. It is scripted to give the learner a point of view on a precise field: archaeology. The form of the quest limits the repeatability of the game (in Woodment for instance the business game can be played many times) but integrates the learning activities in a consistent environment. Additionally, the quest mixes real and virtual activities, calling for a study of mixed reality games.

\subsection{Mixed reality games}

Learning Games have sometimes some limitations when it is necessary to transfer the knowledge learned in other situations. It could be useful to create situations closer to reality, especially for the acquisition of professional skills (e.g. technical gestures or procedures performed in complex environments). To achieve this, a solution is to go beyond the conventional use of computers and to use Mixed Reality techniques. According to Milgram and Kishino, Mixed Reality (MR) refers to a continuum that connects the physical and digital worlds and that is schematically spread between two extremes [25]:

- Augmented Reality (AR), where the real world is enriched by virtual information;

- Augmented Virtuality (AV) where, in contrast, a virtual world is enriched with real objects (e.g. by using tangible interfaces to manipulate virtual objects).

Several devices can be used for implementing MR, including see-through Head Mounted Displays (HMD), mobile devices such as digital tablets or smartphones, digital tabletops, or tangible interfaces that control or represent virtual information. Nilsen, Linton \& Looser have shown that augmented reality kept both the benefits of real activities (especially communication between people) and the benefits of virtual environment, including the possibility of introducing virtual characters [26]. Furthermore, adding information to real objects, information that is not perceptible naturally, is of great interest for educational situations. Some studies, such as [27], show that augmenting physical artefacts with associated information, facilitates the understanding of concepts. 
More recently, David et al. studied how physical artefacts (industrial machines or computers) could be augmented with digital data to promote just in time learning [28]. Mixed Reality seems quite suitable for the learning of gestures, actions and operations, particularly in mobile and work situations.

Mobile devices give the opportunity to develop an active pedagogy, favoring learning in authentical context and allowing the use of the natural environment as a source of information. Certain types of knowledge needs students to learn through observation and are not always easy to teach during the course of a traditional class or with a web-based learning environment. Mobile applications prove to be useful in this case. For instance, Explore! [29] supports young students learning ancient history during a visit to archaeological parks. The game allows students to explore 3D reconstructions of historical buildings, objects, and places, and also contextual sounds are played in order to recreate the historical atmosphere and enhance the overall user experience. Another example could be found in the PRISMA project, the real scene is enhanced by multimedia personalized interactive information to increase the tourist experience of the user [30]. In the archaeology field, the new opportunities offered by using Augmented Reality provide solutions "to combine the strengths of a computer-based approach (reproducibility, experimentation, computer reconstruction) with archaeological phenomenology (embodied experience in the field)" [31].

So, there have been numerous attempts to design and to implement pervasive games, in general, and to deploy pervasive games for learning purposes, in particular. The majority of those pervasive games failed quite badly [32]. The main reason is that didactic aspects are difficult to design and to integrate during the storyboarding of the interaction between the real world and the virtual world.

While it is still too early to draw conclusions about the effectiveness of MR on learning [33], learning outcomes seem to be rather short-term. In order to overcome these short-term limitations, more elaborate learning scenarios should be designed. By coupling Mixed Reality and Learning Games, it is possible to combine from one hand motivational and situated aspects of MR and on the other hand fun and scripted activity of LG. This point was the main goal of the SEGAREM project [34]. During this project, an experimental study has been conducted to evaluate the impact of Mixed Reality interactions on learning. A Mixed Reality Learning Game (MRLG) was designed to teach Lean Management principles in an engineering school. Some actions are carried out with mixed reality, by using tangible interfaces over tabletops (e.g. a physical glue gun with an infrared light is used to stick virtual elements). The comparison between a learning session with the MRLG and an other without mixed reality interaction revealed a tendency for the MRLG situation to effectively have a positive impact on learning, particularly the understanding of theoretical concepts is favoured [34].

Despite often using less cutting edge technologies as the "visual display" oriented examples provided in [25], many Pervasive Games (PG) use augmented reality [35, p. 13]. They cannot be situated on either extreme of the virtuality continuum due to the tight link between the virtual and the real world existing in the action within the game. Chochliourios et al. even abstract themselves from the MR continuum altogether and propose the following definition: "Mixed reality is one where multiple devices allow views and interactions within a given context" [36, p. 476].

If we refer to Montola, Stenros and Waern, this "context" would be at the core of what defines a PG. They introduce the notion of PG based on the notion of boundaries inherent to the systems defined by more classical games. According to them pervasive games offer three types of extension of boundaries [35, p. 20 25]:

- Spatial expansion: is the game restricted to a certain area or does it provide mechanics to expand it?

- Temporal expansion: is the game time strictly delimited?

- Social expansion: how the interactions between players and non-players handled in the game or how individual get involved in the game?

PG offer a new concept that combines the properties and advantages of three worlds: the physical, the social and the virtual [37]. Pervasive Games use mobile devices and location-based scenario in order to immerse the players. They support social interactions and structure them (inside quests, guilds or gangs). This kind of game is currently little used in education.

The work presented in this paper is clearly situated within the trend of mixed reality and pervasive games described in this section. The originality of the Janus project lies in the exploration of the possibilities of an educational MORPG ${ }^{1}$, which combines both real and virtual worlds.

\footnotetext{
${ }^{1}$ We attract the reader's attention to the fact that we removed the first $\mathrm{M}$ - for Massively - as, despite drawing inspiration from such games and aiming at handling a community, our prototype is not expected to become "massively" multi-player to the scale of commercial MMORPGs in the foreseeable future. All the same, we have conceived the system as to allow the constitution of a local community of archaeology enthusiasts.
} 


\section{A learning scenario for a MORPG based on mixed reality}

Before entering the description of the scenario, we will describe the environment on which we build our game. We decided to reuse BrowserQuest ${ }^{2}$, an open-source HTML5 retro-gaming styled MORPG. It has two main features at its core that decided us to reuse it:

- as a browser game both for PC and mobile devices, it can be used for MR applications;

- it provides in-game communication mechanisms required for collaborative learning.

Being open source, we have here a highly customizable tool, but it was not designed as a game engine, which should be taken into account by developers.

\subsection{An exploration game}

Our game, like BrowserQuest, is an exploration game. The exploration will lead players to glean information and missions from NPCs (Non-Playing Characters), to meet and talk with other players, including guild members. In Figure 1, we take into account the explorative nature of the game, one should therefore not perceive it as a linear timeline, but more as a spatial representation: the left being further away from the end of the quest than the right side. But the player is free to evolve in any direction. The dotted arrows indicate that new behaviours are unlocked, the dashed arrows point out that a reference is made to another task or NPC and when an event triggers an activity, we use plain arrows. This representation allows insuring that there is actually a path linking all steps in the scenario.

In such a setting, the progress of the player(s) is based on events that affect the narrative and the tasks at hand. In the rest of this section, we will explain how we handle these events in order to play our scenario, especially from the standpoint of its mixed-reality and collaborative aspects.

\subsection{A mixed approach: real and virtual experiences}

The approach chosen in this scenario is different from other existing initiatives, such as that of Chochliouros et al., who work on the gamification of museum exhibits [36]. In our scenario, it is the exact contrary as the museum and other real work ressource serve a purpose in the quest of the players. Still, the game shares with that of Chochliouros et al. a certain pervasivity, that can be traced back to the typical genres of pervasive gaming: the "urban adventure" [35].

\footnotetext{
${ }^{2}$ Repository maintained by the community https://github.com/ browserquest/BrowserQuest.

Description by the developers http://www.littleworkshop.fr/ browserquest.html.
}

In the scenario described above, we isolate three modalities respective to the role of the real world in the activity (virtual, mixed and real world experiences). Five punctual phases are described in the scenario. They have been numbered accordingly. The mutualization task being transversal to the game play it is therefore not concerned by this decomposition. We will henceforth refer to the tasks by their number in figure $1^{3}$.

Some actions $\left(1,3,4^{\prime}\right)$ take place exclusively in the virtual environment. This is the case of the introduction of the game, where the players learn about the storyline and their global role in the scenario.

This is also the case of the exploration of BrowserQuest, which is of course solely virtual. All the same, being virtual does not mean it is disconnected from the real world: the underlying map contains representations of real places. These places act as landmarks of the real world. When visiting archaeological sites, the learners can access this map from any place thanks to mobile devices, and so access information on that place and linked quests. Indeed aids provided for real world tasks come from the virtual environment. With this respect the learners need to be able to recognize in the virtual environment, the places they have visited in real life. To strengthen this link between real and virtual, geolocation could be used as a means for the environment to provide contextual aid.

For instance, the "taking pictures" activity (4) is dedicated to allow the learners to realize that various gallo-roman monuments exist in their city. They are therefore asked to photograph some of them. This allows explaining some of the standards of pictures used in archaeology archives. Learners are also asked to notice monuments that will later be at the center of other activities. To help players to find all the expected monuments, a contextual aid can be provided by NPCs depending on where the user is, giving more precise information if the user is close to the concerned location or conversion functions could be devised to move approximately the character in the browserquest map so that it indicates to the player when they come near a point of interest ${ }^{4}$. Yet we do not consider this activity as mixed, as a player having studied thoroughly the task description and knowing very well the city, could finish it without any connection to the system, and with no other device than a camera.

On the other hand, certain activities require the user to be in a specific location both in the virtual world (place on the map/url) and in the real world (near an artefact). In this case, the real artefact is contextualized by its representation in the system. For such an issue, geolocation is inadequate in that

\footnotetext{
3 and displayed (like this).

${ }^{4}$ Neither functionality has been implemented to this day.
} 


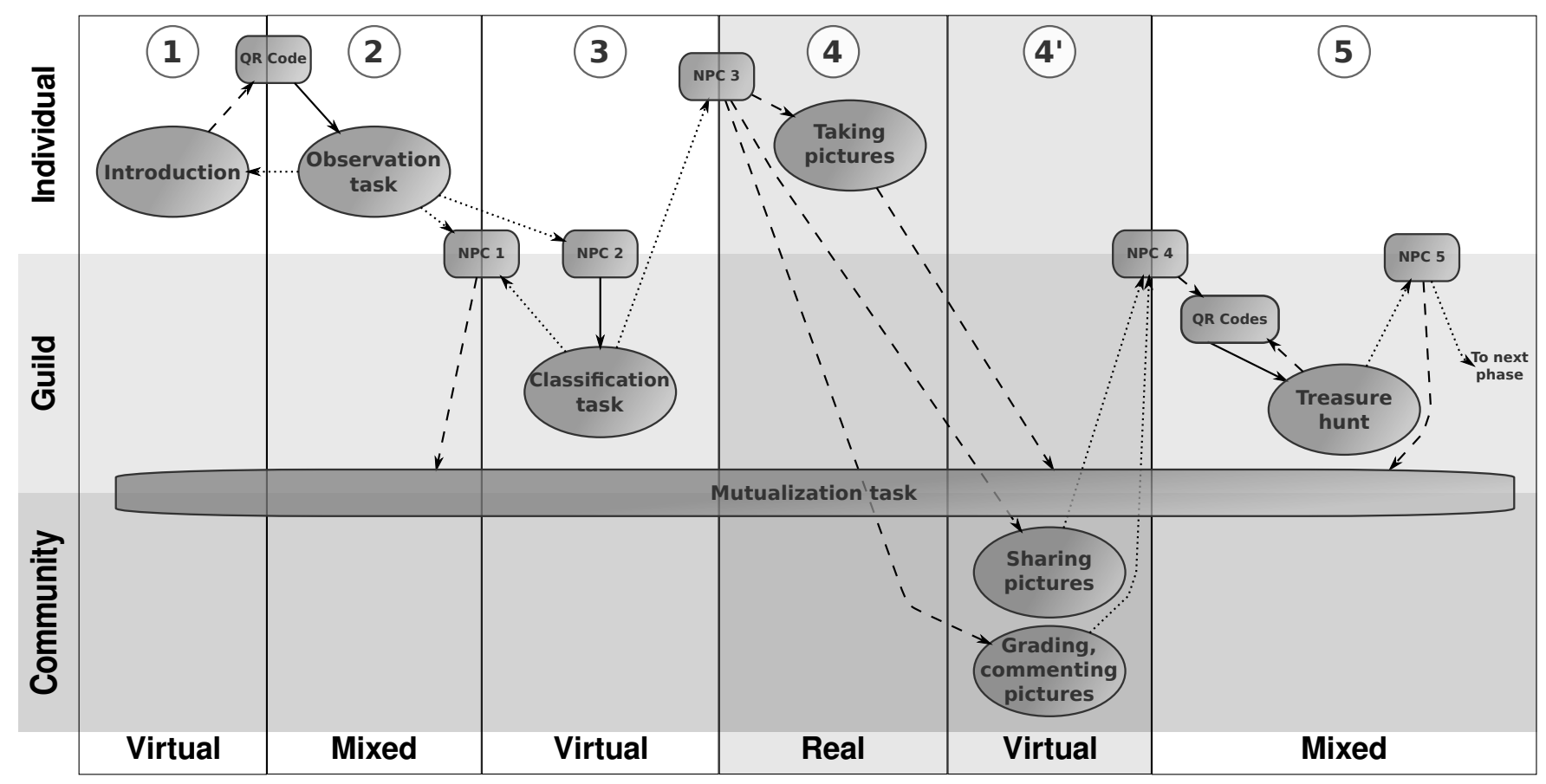

Figure 1. The game scenario displaying activity (real, mixed or virtual) and actor (individual, guild or community) types

it describes the players or their device, more than it describes the environment. In this case, we resorted to QR codes that both allow ensuring that the players are in contact with the considered artefact and that they will load the appropriate url to perform the task at hand.

In the "observation task" (2), the players are asked to observe a monument and need to answer questions on site using a mobile device. The execution of such activities being highly circumstantial, the QR code triggers the task and does not just unlock it (hence the solid arrow in Figure 1). Likewise in the treasure hunt (5), the principle is that the players are asked to find an item in the Gallo-Roman museum of Lyon-Fourvière ${ }^{5}$ based on archaeological questions. The players answer by scanning a QR code associated to an artefact thus triggering the next question in the quest.

\subsection{A combination of individual, team and community experiences}

In order to keep a strong motivation in the game, we have decided to organize a learning quest where students are grouped into guilds and can also carry out social activities involving the whole community of learners. We describe in this section how the proposed scenario is meant to enhance collaboration into the teams and social interactions into the global community.
The "observation task" (see Figure 1) is an example of a task we consider as individual: the players can play right after entering the game without waiting for others. Such a task is also meant to help them learn the specialization associated to their role. We have distinguished three roles that are trades in the archaeology domain: epigraphist, architect and art historian. This is the object of an individual progression, associated to an indicator, to be presented to the user as recommended in [20].

In a way inspired by jigsaw classrooms (cf. Section 3.1 p. 3), individual activities (2) can serve the group goal as a guild is constituted of players of different roles. The information gathered by players in individual tasks is meant to be reused for the progress of the team. All teams have the same goal that is to build a virtual information panel for an archaeological site. The information panel constitutes a virtual representation of the team's progress. It is therefore accessible to all players at any moment for monitoring purpose. We use an etherpad ${ }^{6}$ to implement it. Each quest aims to provide the team with information to fill in the notice. This is why the representation of the mutualization task in figure 1 is transversal. The mutualisation task serves as a guideline for the different teams. We can point out that there is a game incentive here. The vizualisation of an added element on the information panel is a motivating item. Furthermore, another game incentive 
results from a competition between the teams, since at the end of the game the best virtual notice should be issued to be physically set in the real site. This task is mainly carried out from within the guild, but overlaps the community level as well because of this competition (cf. Figure 1).

An example of such group progress is provided in the scenario. When all players in a guild have completed the "observation task" (2), a flag is lifted so that the NPC1 adapts its message to the task outcome. It reminds each player of the most important facts $\mathrm{s} /$ he has gathered in the tasks and suggests them to go on a mutualization task, i.e. to write them down in the etherpad, which allows both synchronous and asynchronous edition and also provides chat facilities.

Other tasks that take place later in the game require the guild members to collaborate in order to achieve completion. For example, in the "classification task" (3) we expect the players to communicate to solve the riddle: depending again on their role, the players are provided with different pieces of information, some gleaned in activity (2). All are necessary to solve the puzzle. Another example of this adaptation of jigsaw classrooms can be found in the treasure hunt (5). The players are not only finding artefacts in the museum, they are also provided with clues. The treasure hunt is split into two smaller quests, the clues of which need to be combined to solve the final riddle. After each task, the last information gathered is reminded to the player by an NPC (cf. NPC1 or 5).

The part played by the guild in the quests is both meant to support players' involvement and the co-construction and appropriation of knowledge by learners. We therefore aim at enhancing collaboration within teams and social activities within the global community. Indeed, some tasks involve the players at community level. For example, the "taking picture" task (4), linked to NPC3, can be carried out individually by players, but its outcome is meant to be shared with the community $\left(4^{\prime}\right)$. The other teams' members can rate these photographs and comment them $\left(4^{\prime}\right)$. We incite players to participate by making their social indicator evolve according to their level of participation in this quest (posting photos, rating and commenting them). This indicator can be used to award community-based achievements, while the evaluation provided thanks to it is in term computes to unlock individual and guild successes - i.e. game-based achievements [23].

\section{Implementation}

After designing the scenario, we have implemented specific software for supporting the activities to which the browserquest environment points. Following our agile philosophy, we have decided to develop first a slightly shortened scenario, focusing on the guild activities. This part of the scenario will be tested with a first experiment involving real players. The community activities are delayed to a next phase, since they require a bigger scale protocol. In this shortened scenario, we have removed the greyed activities of Figure 1 and the mutualization task. Indeed the mutualisation task looses interest without the community aspects.

This has led us to implement three prototypes that can be used independently from the rest of our system. They are currently $\propto$-stage software (lacking various features) but are all functional and open-source ${ }^{7}$.

\subsection{PhotoSwipe.Quizz}

As indicated by its name, this is a fork of PhotoSwipe ${ }^{8}$. This module allows to generate automatically a quizz that will ask the player questions the answer of which are an image (see Figure 2). It uses a JSON formalism to generate the quizz based on a text file and various image files. The system integrates a very rough traces gathering module. As we plan to interconnect with a real interaction traces repository, we will need to make adaptations to this module.

PhotoSwipe.Quizz is used to carry out the observation task and modifies local storage variables to enable browserquest to detect completion of the task (cf. dotted arrows to NPC $1 \& 2$ ). To help the player complete the task, the system provides a feedback giving them hints leading to the solution ${ }^{9}$ whenever an erroneous solution is selected. When the task is completed the player is given additionnal feedback concerning his or her trade in the game. The information gathered through the task will be made available to the players, through NPCs, before it needs to be reused, for instance in the classification task.

\subsection{WESort}

Before detailing the capabilities of the application for the classification task, we need to describe it further. The users can connect simultaneously or not. As illustrated on Figure 3, they have a list of archaeological items represented with an image, a title and some text and they have to place them in a double entry table. The players are given a set of clues that require some competences acquired through the game to be interpreted and each clue is therefore addressed to one player in particular. But to place properly each card, pieces of information coming from at least two clues are required.

\footnotetext{
${ }^{7}$ See our github page: https: / / github.com/ janus-IMU

$8_{\text {https: / / github.com/codecomputerlove/PhotoSwipe }}$

${ }^{9}$ In Figure 2, the feedback introduces the distinction between transcription and copy, and draws the player's attention to the superposition of characters.
} 


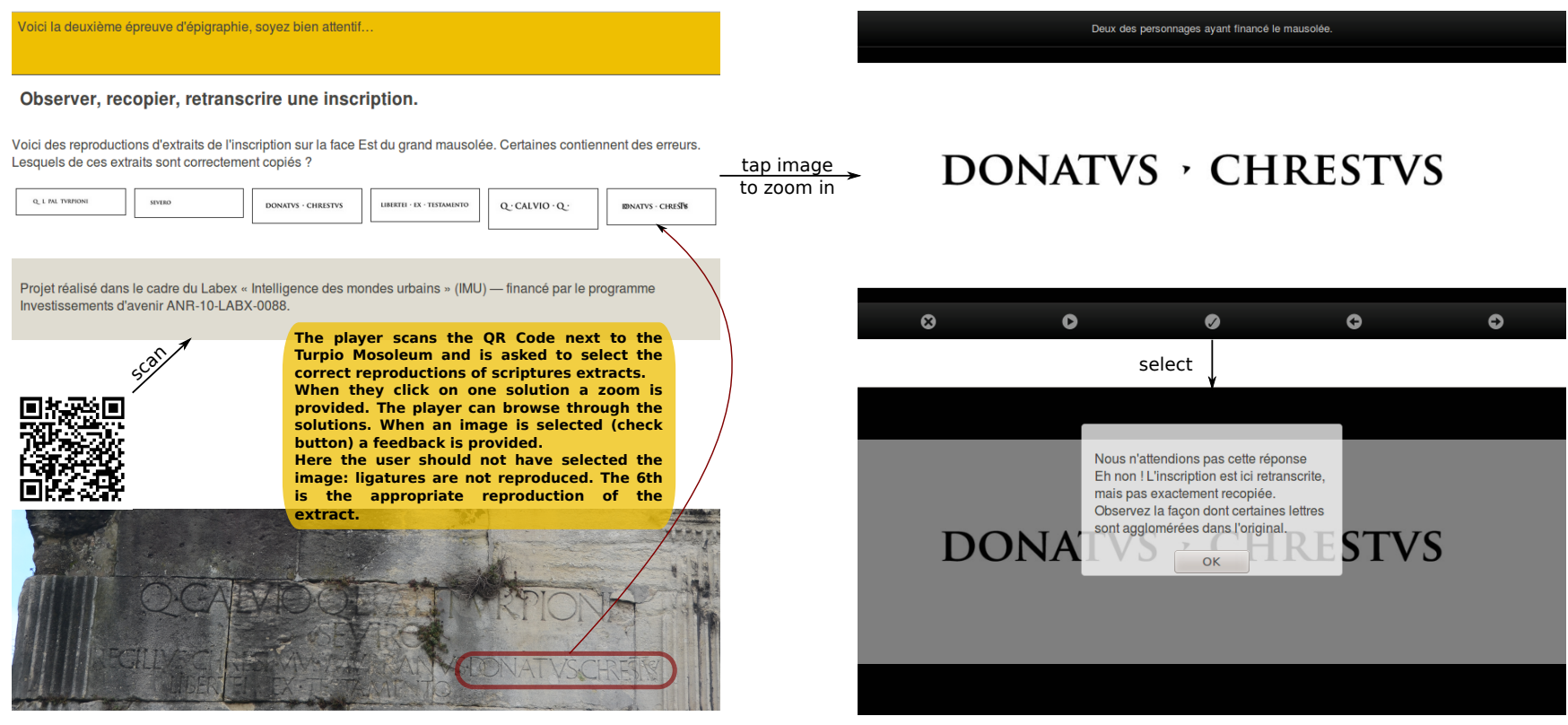

Figure 2. Screen capture and functionning of PhotoSwipe.Quizz

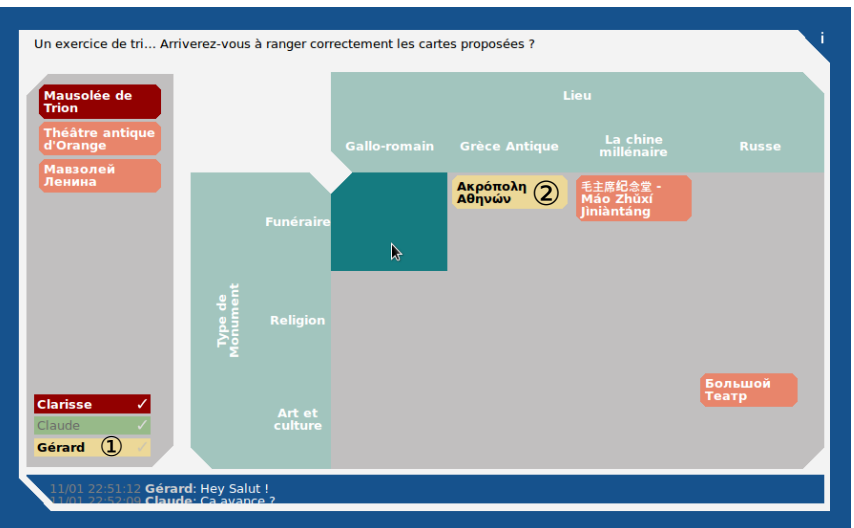

(The content here is not that of the activity)

When connected the user knows which members of the team are connected at the time (here Clarisse - the user whose viewpoint we are displaying - and Gérard). The users with a white tick box have asked for a validation (Gérard is preventing the validation to occur(1). The colored cards are associated to the user manipulating them (here Gérard has selected the yellow one (2), while Clarisse is preparing to move the "Mausolée de Trion" card into the ("Funéraire", "Gallo-romain") cell.

Users can check the information present on each card - upper right screenshot - . It contains : a title, a description, an image, a comment zone (here, Clarisse asked a question) and the last 5 positions it occupied (when and who moved the card).

The " $\mathrm{i}$ " on the top-right corner provides the extra-information to solve the puzzle (the jigsaw inspired clues).

Finally, the chat box can be enlarged for the users to communicate (lower right screen capture).
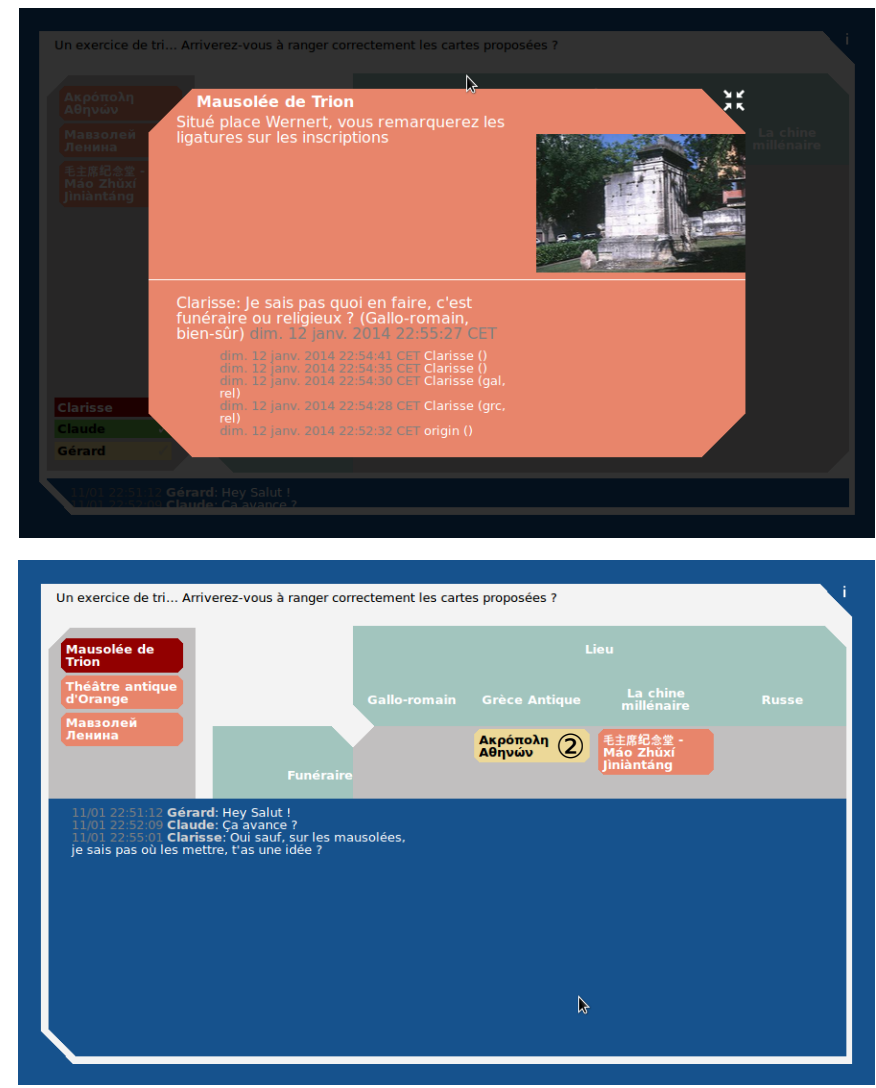

Figure 3. Screen capture and functionning of WESort

The application allows them to move the cards (when a player selects a card the other players have to wait until it has been released to select it, cf. card (2) in
Figure 3), add comments to each card (upper right image in Figure 3), chat with each other (lower right image), and ask for a validation of the solution (checked 


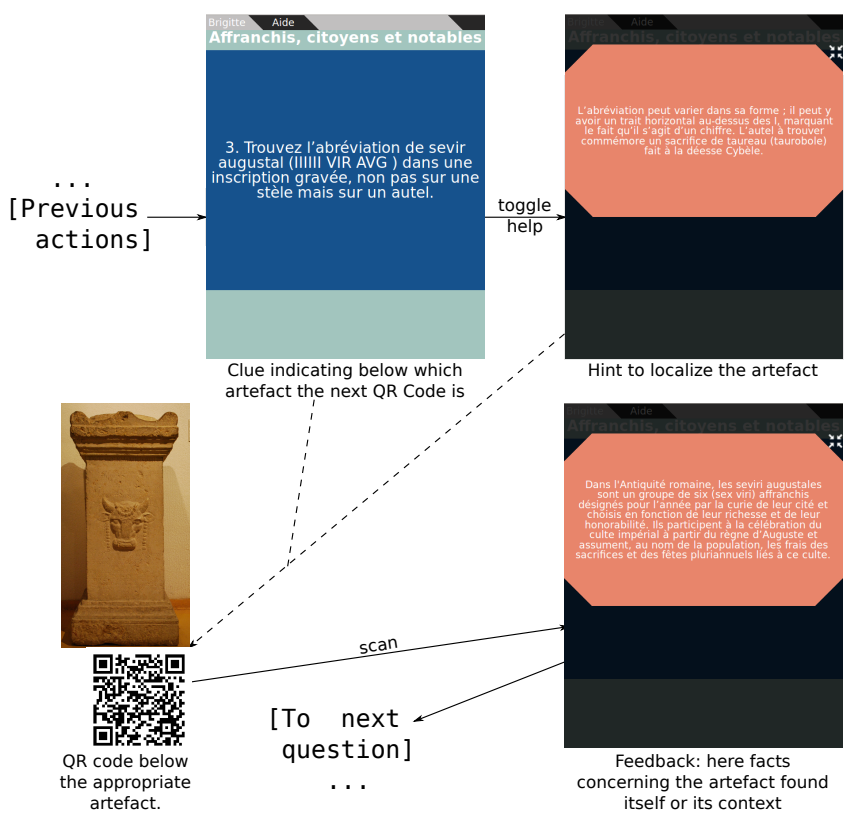

Figure 4. Screen capture and functionning of QuestsRCodes

player names in upper left image). To force players to exchange and prevent them from using "brute force" to solve the puzzle, the feedback is only provided when all players have requested a validation.

The exchange between the players is also meant to help them acquire the concepts according to which they are to be classified. To favor the acquisition of the terminology, the categories according to which cards are to be classified can be randomly displayed (line or column / position within the line or column). This is meant to prevent players from referring to the table cells through numerical coordinates. force them to use the actual category name in their communication.

The application allows to store the state of the game. The generation of the board also interprets a JSON file. The code is also open-source and uses node.JS and mongoDB.

\subsection{QuestsRCodes}

The application created for the treasure hunt is also open-source and generates, based on a JSON file, a set of QR codes to be printed out. The QR codes are tagged with a location in order to facilitate the installation of a quest. The JSON file also provides data for the system to display the question asked to the players and find the next one based on the code scanned (see Figure 4).

Each question provides a context for the QR codes to be interpreted. A single artefact - and its associated QR code - can be the solution to riddle A, trigger specific feedback when scanned in the course of solving riddle $\mathrm{B}$ and default feedback when the player is addressing riddle $\mathrm{C}$.
This application was tested at the Lyon gallo-roman museum during a weekend and beyond $3 \mathrm{G}$ carrier issues, it pointed out the need for the implementation of a "hint" feature, before launching the experiment.

\subsection{Modular view}

Through this feasability study, we have made available certain elementary blocks associated to activities. Enriching the functionnalities of these elementary blocks or adding new ones is possible, thus providing additional kinds of activities.

At this stage, we propose elementary blocks but also underline how the combination of elementary blocks is used to compose a scenario. As illustrated in this paper, this composition can be supported by a spatial view. The activity sequencing is represented by links and NPCs are also key items for information transmission. Our research activity deals with collaboration and social issues in the game. These aspects are supported by both the guild and community concepts in the game. As illustrated in Figure 1, it is crucial to identify clearly the target (individual, guild, community) for each activity. A mixed combination of these kinds of activity clearly provides richer possibilities. For instance, in the scenario described in this paper, individual tasks can reinforce personal skills, whereas guild activities allow sharing skills, explanations and reformulation.

\section{Discussion and perspectives}

The JANUS project is a feasibility study leading to a set of prototypes which are to be completed and linked together for an experiment currently in preparation. Pervasive in nature, it examines the possibility to provide a social, mixed reality, serious game to raise awareness about archaeology as well as to promote the city's monuments. We described in this paper the design choices we have made in the implementation process and especially in the learning scenario. We performed the connection between the virtual and the real world, by representing real places in the virtual map, by identifying artifacts using QR codes. In a near future, we will add contextual information for items in the game using geolocation. To complete the quests the players evolve as individuals or as members of a team or as members of a community.

\subsection{Social extensions}

This social component — individual, guild and community level of activity - adds a layer to the problem of collaboration as described in [20] (cf. section 3.1 p. 4). While recommendation (iv) players with different abilities — does not require 
adaptation to our context ${ }^{10}$, the decisions we took provide a lead for an extension of recommendation (i) to a social context. With the team final goal (creating an information panel for a monument), by allowing players to choose among all team productions an actual panel, we introduce a tension between perceived individual and team utility (voting to favor one's own team) and the perceived community interest (sharing valuable resources with people outside the community, here the people visiting the archaeological site). To this tension, one has to add the tension between the different social consequences for individuals of the behaviors used to favor individual or team utility.

This does not deny the possibility to apply the recommendation at the level described in Zagal et al.'s study. We could extend our scoring mechanisms by computing the team and the individual indicators according to different criteria: the individual score favoring the quickness of responses, the team score penalizing errors harsher. Given a choice, the learners would be able to choose between taking the risk of an error (individual utility) or involving others' knowledge to eliminate as much uncertainty as possible through discussion (group utility).

This leads directly to another recommendation: (iii) - tracing payoff back to one's decision. In the case of a closed output activity (such as the classification task), providing feedback on a user action can easily be computed. But the regulation role of the community seems noteworthy. Indeed the community can be instrumental to providing feedback on actions performed in more open tasks in terms of outcome (a set of photos or writing a text) than a fully computational solution. Additionally the social actions of the users (sharing pictures for instance) can be traced to influence the progress of the game (e.g. after sharing five photos among its members a flag allows a guild to unlock the next phase of the game, cf. NPC3 in Figure 1).

\subsection{Consequences of/on pervasivity}

If successful in practice, this would further anchor the game in the social web paradigm by "harnessing collective intelligence" [38]. In the long run, this feature could be taken further by performing real community tasks. After evaluating photos and notices, the various outcomes could provide the basis for a community written article about city monuments, for instance in a wiki. Ideally, such a game would serve to gather archaeology enthousiasts, help them to develop sufficient domain knowledge to get involved in

\footnotetext{
${ }^{10}$ In the long term, one can imagine addressing this point though. With a larger communities, scenarios where guilds specialize and need to collaborate with one another to solve larger scale tasks are to be considered.
}

participative science experiments (such as listing galloroman mason's mark in private parts of the city of Lyon). If the game component is kept in such social extensions $^{11}$, the pervasivity would be dramatically expanded spatially (by definition the position of a yet to discover mason's mark cannot be specified a priori) and temporally (as players might, in the course of their daily life, be brought back into the game just by noticing they are surrounded by blocks that could be gallo-roman).

The mixed reality aspect of the game is not without social consequences either. By bringing players to actual real life artefacts, the environment relinquishes control over user interactions. Players are free to communicate in the real world or to perform tasks together with team members or other players. These untraced interactions should not be neglected in later analyses nor ignored in the game design. Let's follow on the example we gave for computing individual task scores: computing team work solely by counting chat interactions during the task would negate the possibility for players to interact in the real world. This would be problematic in that the task actually creates the possibility for players to be physically able to communicate.

This makes the actual city locations part of the environment of the game in exactly the same way as BrowserQuest. The location of the "observation task" initiating our scenario is in effect an entry point to our game through the presence of a $Q R$ code that can be scanned by any passer-by or bystander curious about players present in the premises. This exemplifies the concept of social expansion inherent to PG. This underlines the issue of how to favor entering a mixed reality game such as this one and the consequences of design decisions in term of guild constitution and community engagement. In our future works, we plan to conduct several experiments with people of different backgrounds to study the implications of these decisions on their progress in the learning scenario and on the level of knowledge acquired in the archaeological domain at the completion of the game.

\subsection{Experiments}

Several steps of the scenario were tested. The "treasure hunt" activity (5) was implemented during two open days at the the Gallo-Roman museum of LyonFourvière $^{12}$. It came out that mixing virtual and real activities is not an easy task. Although the software had been carefully tested, an unexpected problem raised while users tried to pursue their quest inside the museum: the connection to the network was quite

\footnotetext{
$\overline{{ }^{11} \text { This could be done using classical gamification mechanics such as }}$ points, levels and leaderboards [39, chap. 3].

12 http : / / ww . musees-gallo-romains.com/presse/2013_fete_ de_la_science
} 
impossible except for the people subscribing to the one carrier we had used in our tests. The other ones were unexpectedly deprived of internet connection. This leads to a methodological technical consideration. When in a zone where WiFi access is not assured, we need to be able to download the whole quest on the mobile device and include a QRCode reader in the wep app ${ }^{13}$ before allowing the beginning of the quest, especially if it takes place inside a building.

Additionnally, tasks (1) and (2) were tested at the "innovative SHS" event in May $2013^{14}$. This was not a proper experiment but allowed to test the interaction means and verify proper communication to BrowserQuest of the outcome of the observation task.

As mentionned earlier, further experiments should be carried out, first at the group level - tasks $(1,2,3,5)$ in Figure 1 - before adding the social component $\left(4,4^{\prime}\right)$.

\subsection{Genericity of the approach}

The aim of the work presented in this paper was to reach several challenging objectives presented in section 2:

- reenforcement of the acquired knowledge by a "learning by doing" pedagogy ;

- introduction of collaborative learning ;

- and management of social activities.

As explained in the paper, the archaeological area is a domain where the complementarity of these objectives is extremely fruitful. However, the approach proposed in the paper can be applied to any subject where these three items are challenging issues. We can imagine that many hot topics (e.g. ecology, medical domain) can be eligible, since communities can easily emerge with the will to learn more about the domain by using new and attractive educational methods.

Acknowledgements. This work was supported by the LABEX IMU (ANR-10-LABX-0088) of Université de Lyon, within the program "Investissements d'Avenir" (ANR-11-IDEX-0007) operated by the French National Research Agency (ANR).

We would like to thank our archaeologist colleagues for their participation in this project and involvement in the various field tests performed. Additionnally, the pictures in Figures 2, 3 and Figure 4 were taken respectively by MarieOdile Rousset, Myriam Fincker and Alexandre Rabot. The archaeological content in the activities of Figures 2 and 4 were

\footnotetext{
13 https://github.com/dwa012/html5-qrcode is a potential solution, but will raise the issue that such code is only executable in the most recent mobile OSes excluding some users from the experiment. Resorting to manually copied numerical codes, could be a temporary solution until modern mobile browsers are more widely available.

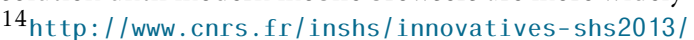
presentation.htm
}

respectively designed by Jean-Claude Decourt \& Jean-Pierre Girard, and by Jean-Pierre Girard \& Claudine Maréchal. Myriam Fincker, Jean-Charles Moretti, Anne Pariente and Emmanuelle Vila contributed to the content of the scenario.

We also thank the Musée Gallo-Romain de Lyon for letting us test our application on-site.

\section{References}

[1] Kniberg, H. (2007) Scrum and XP from the Trenches - How we do Scrum (C4Media). URL http://www. infoq.com/ minibooks/scrum-xp-from-the-trenches.

[2] Flynn, R., McKinnon, L., Bacon, E. and Webb, J. (2011) Maritime city: Using games technology to train social workers - some initial results. In AnACLETo, J., Fels, S., Graham, N., Kapralos, B., Saif El-Nasr, M. and Stanley, K. [eds.] Entertainment Computing ICEC 2011 (Springer Berlin Heidelberg), Lecture Notes in Computer Science 6972, 415-418. doi:10.1007/9783-642-24500-8_55, URL http://dx.doi.org/10.1007/ 978-3-642-24500-8_55.

[3] Rosenbloom, A. (2004) Introduction. Commun. ACM 47(8): 28-31. doi:10.1145/1012037.1012058, URL http : // doi .acm.org/10.1145/1012037.1012058.

[4] Purdy, J.P. (2010) The changing space of research: Web 2.0 and the integration of research and writing environments. Computers and Composition 27(1): 48-58. doi:10.1016/j.compcom.2009.12.001, URL http://dx. doi .org/10.1016/j . compcom. 2009.12.001. Composition 2.0.

[5] Marty, J.C. and Carron, T. (2011) Observation of collaborative activities in a game-based learning platform. IEEE Trans. Learn. Technol. 4(1): 98-110. doi:10.1109/TLT.2011.1, URL http://dx.doi.org/10. 1109/TLT.2011. 1.

[6] Seuire, K. and Jenkins, H. (2003) Harnessing the power of games in education. Insight 3: 3-35. URL http:// website.education.wisc.edu/kdsquire/ manuscripts/insight.pdf.

[7] Kirriemuir, J. and Mcfarlane, A. (2004), Literature review in games and learning. URL http: // telearn. archives-ouvertes.fr/hal-00190453. A NESTA Futurelab Research report - report 8.

[8] Araya, R., Jiménez, A., Bahamondez, M., Dartnell, P., Soto-Andrade, J., González, P. and Calfucura, P. (2011) Strategies used by students on a massively multiplayer online mathematics game. In Leung, H., Popescu, E., Cao, Y., Lau, R. and Nejdl, W. [eds.] Advances in Web-Based Learning - ICWL 2011 (Springer Berlin Heidelberg), Lecture Notes in Computer Science 7048, 1-10. doi:10.1007/978-3-642-25813-8_1, URL http://dx.doi.org/10.1007/978-3-642-25813-8_1.

[9] Benassi, A., Orlandi, C., Cantamesse, M., Galimberti, C. and Giacoma, G. (2011) World of warcraft in the classroom: A research study on social interaction empowerment in secondary schools. In Proceedings of The 5th European Conference on Games Based Learning: 35. URL http://connection.ebscohost. com/c/articles/78120320.

[10] Johnson, N.F., Xu, C., ZhaO, Z., Ducheneaut, N., Yee, N., Tita, G. and Hui, P.M. (2009) Human group 
formation in online guilds and offline gangs driven by a common team dynamic. Phys. Rev. E 79: 066117. doi:10.1103/PhysRevE.79.066117, URL http://link. aps.org/doi/10.1103/PhysRevE.79.066117.

[11] JANG, Y. and Ryu, S. (2011) Exploring game experiences and game leadership in massively multiplayer online role-playing games. British Journal of Educational Technology 42(4): 616-623. doi:10.1111/j.14678535.2010.01064.x, URL http://dx . do i org/10.1111/ j . 1467-8535.2010.01064.x.

[12] Egenfeldt-Nielsen, S. (2006) Overview of research on the educational use of video games. Digital Kompetanse 1(3): 184-213. URL http://itu.dk/people/ sen/papers/game-overview.pdf.

[13] Wenger, E. (1998) Communities of practice:learning as a social system. The Systems Thinker 9(5).

[14] Paraskeva, F., Mysirlaki, S. and Papagianni, A. (2010) Multiplayer online games as educational tools: Facing new challenges in learning. Computers $\mathcal{E}$ Education 54(2): 498-505. doi:10.1016/j.compedu.2009.09.001, URL http://dx.doi.org/10.1016/j.compedu.2009. 09.001.

[15] Lavoué, E. (2012) Towards social learning games. In Popescu, E., Li, Q., Klamma, R., Leung, H. and Specht, M. [eds.] Advances in Web-Based Learning ICWL 2012 (Springer Berlin Heidelberg), Lecture Notes in Computer Science 7558: 170-179. doi:10.1007/9783-642-33642-3_18, URL http://dx.doi.org/10.1007/ 978-3-642-33642-3_18.

[16] Bouvier, P., Sehaba, K., Lavoué, E. and George, S. (2013) Using traces to qualify learner's engagement in game-based learning. In Advanced Learning Technologies (ICALT), 2013 IEEE 13th International Conference on: 432-436. doi:10.1109/ICALT.2013.132, URL http:// dx. doi . org/10.1109/ ICALT. 2013.132.

[17] Voulgari, I. and Komi, V. (2011) Handbook of Research on Improving Learning and Motivation Through Educational Games: Multidisciplinary Approaches (Information Science Reference), chap. Collaborative Learning in Massively Multiplayer Online Games: A Review of Social, Cognitive and Motivational Perspectives, 307394. doi:10.4018/978-1-60960-495-0.ch018.

[18] Aronson, E. (1978) The jigsaw classroom (Beverly Hills, CA: Sage Publishing Company).

[19] Johnson, D., Johnson, R. and Holubec, E. (1993) Circles of learning: cooperation in the classroom (Interaction Book Co.).

[20] Zagal, J.P., Rick, J. and HsI, I. (2006) Collaborative games: Lessons learned from board games. Simulation $\mathcal{E}$ Gaming 37(1): 24-40. doi:10.1177/1046878105282279, URL http://facsrv.cdm.depaul.edu/ jzagal/ Papers / Zagal\%20et\%20a1\%20-\%20Collaborative\% 20Games\%20-\%20Lessons\%20learned\%20from\% 20boardgames . pdf.

[21] Meyer, B. (2009) Fort ancient, ohio: a curricular approach to developing mobile games for tourists. In Proceedings of The 3rd European Conference on Games Based Learning. URL http://connection. ebscohost. $\mathrm{com} / \mathrm{c} /$ articles/48947162.

[22] Adam, G., Bouras, C. and Papazois, A. (2012) Building community and collaboration applications for mmogs.
International Journal of Computer Games Technology : 13doi:10.1155/2012/969785.

[23] Konert, J., Gerwien, N., Göbel, S. and Steinmetz, R. (2013) Bringing game achievements and community achievements together. In The Proceedings of The 7th European Conference on Games Based Learning: 319-328. URL http://issuu.com/acpil/docs/ ecgbl2013-issuu_vol_1.

[24] Wendel, V., Babarinow, M., Hoerl, T., Kolmogorov, S., Göвel, S. and Steinmetz, R. (2010) Woodment: Webbased collaborative multiplayer serious game. In PAN, Z., Cheok, A., Müller, W., Zhang, X. and Wong, K. [eds.] Transactions on Edutainment IV (Springer Berlin Heidelberg), Lecture Notes in Computer Science 6250, 6878. doi:10.1007/978-3-642-14484-4_7, URL http: / / dx . doi.org/10.1007/978-3-642-14484-4_7.

[25] Milgram, P. and Kishino, F. (1994) A taxonomy of mixed reality visual displays. IEICE Transactions on Information Systems E77-D(12): 1321-1329. URL http://etclab.mie.utoronto.ca/people/paul_dir/ IEICE94/ieice.html.

[26] Nilsen, T., Linton, S. and Looser, J. (2004) Motivations for augmented reality gaming. In Proceedings of FUSE, 4: 86-93. URL http://isites.harvard.edu/fs/docs/ icb.topic122288.files/Nilsen.pdf.

[27] Stedmon, A. and Stone, R. (2001) Re-viewing reality: human factors of synthetic training environments. International Journal of Human-Computer Studies 55(4): 675-698. doi:10.1006/ijhc.2001.0498, URL http://www.sciencedirect.com/science/article/ pii/S1071581901904987.

[28] David, B., Yin, C. and Chalon, R. (2010) Contextual mobile learning strongly related to industrial activities: Principles and case study. International Journal of Advanced Corporate Learning 2(3): 12-20. URL http:// arxiv.org/abs/1001.0642.

[29] Ardito, C., Buono, P., Costabile, M.F., Lanzilotti, R. and Piccinno, A. (2009) Enabling interactive exploration of cultural heritage: An experience of designing systems for mobile devices. Knowledge, Technology \& Policy 22(1): 79-86. doi:10.1007/s12130009-9079-7, URL http://ivu.di.uniba.it/papers/ 2009/KTP09_Ardito_et_al.pdf.

[30] Fritz, F., Susperregui, A. and Linaza, M. (2005) Enhancing cultural tourism experiences with augmented reality technologies. In Mudge, M., Ryan, N. and Scopigno, R. [eds.] The 6th International Symposium on Virtual Reality, Archaeology and Cultural Heritage VAST: 1-6. URL http://public-repository.epoch-net. org/publications/VAST2005/shortpapers/ short2005.pdf.

[31] Eve, S. (2012) Augmenting phenomenology: Using augmented reality to aid archaeological phenomenology in the landscape. Journal of Archaeological Method and Theory 19(4): 582-600. doi:10.1007/s10816-0129142-7, URL http://discovery.ucl.ac.uk/1352447/ 1/Eve_2012_Augmented_Phenomenology.pdf.

[32] JantKe, K.P. and Spundflasch, S. (2013) Understanding pervasive games for purposes of learning. In Proceedings of the 5th International Conference on Computer Supported Education: 696-701. URL 
https://www.researchgate.net/profile/Klaus Jantke/publication/236623004_Understanding_ Pervasive_Games_for_Purposes_of_Learning/file/ 3deec518778f71ff53.pdf.

[33] Anastassova, M. and Burkhardt, J.M. (2009) Automotive technicians' training as a communityof-practice: Implications for the design of an augmented reality teaching aid. Applied Ergonomics 40(4): 713-721. doi:10.1016/j.apergo.2008.06.008, URL http://www.sciencedirect.com/science/article/ pi i/S000368700800118X.

[34] George, S., Michel, C., Serna, A. and Bisognin, L. (2014) Evaluation de l'impact d'un jeu sérieux en réalité mixte. Sticef (in press) .

[35] Montola, M., Stenros, J. and Waern, A. (2009) Pervasive Games: Theory and Design, Morgan Kaufmann Game Design Books (Burlington, MA: Morgan Kaufmann).

[36] Chochliouros, I., McCall, R., Popleteev, A., Avanesov, T., Kamarauskas, T., Spiliopoulou, A., Sfakianakis, E. et al. (2013) (semi-) pervasive gaming educational and entertainment facilities via interactive video-to-video communication over the internet, for museum exhibits.
In Papadopoulos, H., Andreou, A., Illadis, L. and Maglogiannis, I. [eds.] Artificial Intelligence Applications and Innovations (Springer Berlin Heidelberg), IFIP Advances in Information and Communication Technology 412, 474-485. doi:10.1007/978-3-642-41142-7_48, URL http://orbilu.uni.lu/bitstream/10993/9886/ $1 /$ camera-ready.pdf.

[37] Hinske, S., Lampe, M., Magerkurth, C. and Röcker, C. (2007) Concepts and technologies for Pervasive Games - A Reader for Pervasive Gaming Research (Aachen, Germany: Shaker Verlag), 1, chap. Classifying Pervasive Games: On Pervasive Computing and Mixed Reality, 1138. URL http://www.coulthard.com/library/Files/ hinske_2007_classifyingpervasivegames.pdf.

[38] Musser, J., O’Reilly, T. and the O’Reilly Radar Team (2007) Web 2.0 Principles and Best Practices, O’Reilly Radar (Sebastopol (Californie): O'Reilly).

[39] Zichermann, G. and Cunningham, C. (2011) Gamification by Design: Implementing Game Mechanics in Web and Mobile Apps (O’Reilly). URL http : / / shop . oreilly. com/product/0636920014614.do. 